\title{
The effects of spread on abnormal return: Evidence from Tehran Stock Exchange
}

\author{
Samira Vafaee ${ }^{\mathrm{a}}$ and Roya Darabi ${ }^{\mathrm{b} *}$
}

${ }^{a}$ Department of Management and Accounting, South Tehran Branch, Islamic Azad University, Tehran, Iran ${ }^{a}$ Faculty member, Department of Management and Accounting, South Tehran Branch, Islamic Azad University, Tehran, Iran

\begin{tabular}{l}
\hline C H R O N I C L E \\
\hline Article history: \\
Received March 25, 2015 \\
Received in revised format June \\
12015 \\
Accepted June 102015 \\
Available online \\
June 11 2015 \\
\hline Keywords: \\
Tehran Stock Exchange \\
Spread \\
Stock return
\end{tabular}
\begin{abstract}
A B S T R A C T
Spread plays essential role on market liquidity on any stock market. A high gap between bid and ask price may reduce the likelihood of trading activities while a small gap between bid and ask increases the chance of trade execution. In this paper, we present an empirical investigation on the effect of spread on abnormal return. The proposed study collects the necessary information from official statements as well as historical data over the period 2009-2013 reported on Tehran Stock Exchange to examine the relationship between spread and unusual firm performance. Using regression analysis, the study has determined a meaningful relationship between abnormal return and spread.
\end{abstract}

\section{Introduction}

Spread plays essential role on market liquidity on any stock market (Amihud \& Mendelson, 1986). A high gap between bid and ask price may reduce the likelihood of trading activities while a small gap between bid and ask increases the chance of trade execution (Perrakis \& Zhong, 2015). There are literally many studies on measuring the impact of spread on firms' performances (Amihud \& Mendelson, 1989). Mishra et al. (2009) in a survey reported that the bid-ask spread changes substantially around the board meeting dates. They also reported that the actual number of transactions by insiders could increase following the board meetings. Moreover, according to Mishra et al. (2009) there seems to be a significant relationship between spread and the number of insider trades surrounding the board meeting dates. Demirovic et al. (2015) investigated whether accounting data could be reflected in the market-based measures of credit risk and therefore may have no role in describing variations in the credit spread on corporate bonds. They implemented a sample of over 11,000 firmquarter observations with matched equity, bond and accounting data and reported that equity volatility and Merton's distance-to-default could outperform accounting variables in describing variations in the credit spread. Moreover, accounting variables were incrementally informative in describing variations

\footnotetext{
* Corresponding author.

E-mail address: royadarabi110@yahoo.com (R. Darabi) 
in the credit spread when considered in conjunction with market-based measures. They concluded that the profitability ratio was by far the most incrementally informative accounting variable.

Glosten and Harris (1988) developed and used a method for forecasting a model of the bid/ask spread. The spread was split into two components, one due to asymmetric information and the other according to inventory costs, specialist monopoly power, and clearing expenses. The model was examined using NYSE common stock transaction prices over the period 1981-1983. Cross-sectional regression analysis was then applied to build relationship time-series estimated spread components to other stock characteristics. They could not reject the hypothesis that significant amounts of NYSE common stock spreads were due to asymmetric information.

Desai et al. (1998) investigated changes in trading activity around stock splits and their impact on volatility and the adverse-information component of the bid-ask spread. Even after controlling for microstructure biases, they reported a substantial increase in volatility after the split. Changes in total volatility and in its permanent component in their survey were associated positively with changes in the number of trades. This implies that both informed and noise traders could contribute to changes in trading activity. In addition, while the adverse-information component of the spread increased unconditionally after the split, the change was negatively associated with the change in trading activity. They recommended that a crucial determinant of liquidity changes after a stock split was the success of the split in attracting new trades in the security.

Weber et al. (2009) investigated the antecedents and consequences in developing countries of generating a national stock exchange, a core technology of financial globalization. They studied local conditions and global institutional pressures in the rapid spread of exchanges since the 1980s and tried to find out on how conditions at the point of adoption could influence on exchanges' subsequent vibrancy. They reported that international coercion was related to more ceremonial adoption.

\section{The proposed study}

In this paper, we present an empirical investigation on the effect of spread on unusual return on assets. The proposed study collects the necessary information from official statements as well as historical data over the period 2009-2013 reported on Tehran Stock Exchange to examine the relationship between spread and unusual return on assets. The proposed study considers the following to calculated the spread,

$$
\mathrm{BA}\left(\operatorname{SPREAD} \mathrm{i}_{\mathrm{t}, \mathrm{t}}\right)=\left(\frac{\mathrm{AP}-\mathrm{BP}}{(\mathrm{AP}+\mathrm{BP}) / 2}\right) 100
$$

where $\mathrm{BA}\left(\mathrm{SPREAD} \mathrm{D}_{\mathrm{i}, \mathrm{t}}\right)$ is a dependent variable, which represents the difference between bid (BP) and ask (AP) prices. In addition, unusual asset return $\left(A R_{i, t}\right)$ is determined by $A R_{i, t}=R_{i, t}-R_{m, t}$. The study also uses $R I S K_{i, t}$ to measure the systematic risk, which is calculated by measuring the beta associated with each firm. $E F E_{i, t}$ determines the error between actual and predicted earnings, $D P_{i, t}$ represents dividend per share, $L E V_{i, t}$ is associated with leverage, which is calculated as a ratio of total liabilities on total assets, $S I Z E_{i, t}$ calculates the size of the firm, which is measured by taking natural logarithm on total assets, GROWTH $H_{i, t}$ represents the relative growth of the firm and this is calculated by measuring the ratio of market value of equities to book value of the firm and finally, EQi,t states earning quality, which is measured by the ratio of operating cash flow divided by operating profit. The proposed study uses the following regression analysis to study the relationship between abnormal return $(A R i, t)$ and spread.

$$
\mathrm{AR}_{\mathrm{i}, \mathrm{t}}=\beta_{0}+\beta_{1} \mathrm{BA}_{\mathrm{i}, \mathrm{t}}+\beta_{2} \mathrm{RISK}_{\mathrm{i}, \mathrm{t}}+\beta_{3} \mathrm{EFE}_{\mathrm{i}, \mathrm{t}}+\beta_{4} \mathrm{EQ}_{\mathrm{i}, \mathrm{t}}+\beta_{5} \mathrm{LEV}_{\mathrm{i}, \mathrm{t}}+\beta_{6} \mathrm{SIZE}_{\mathrm{i}, \mathrm{t}}+\beta_{7} \mathrm{GROWTH}_{\mathrm{i}, \mathrm{t}}+\beta_{8} \mathrm{DP}_{\mathrm{i}, \mathrm{t}}+\varepsilon_{\mathrm{i}, \mathrm{t}}
$$




\section{The results}

We first present the results of linear regression model for examining any relationship between spread and firm performance. Table 1 presents the results of our survey.

Table 1

The summary of regression technique on Eq. (2)

\begin{tabular}{|c|c|c|c|c|c|c|c|}
\hline \multirow{2}{*}{ variables } & \multicolumn{2}{|c|}{ Non-standard $\beta$} & \multirow{2}{*}{$\frac{\text { Standard }}{\beta}$} & \multirow{2}{*}{ t-value } & \multirow{2}{*}{ Sig. } & \multicolumn{2}{|c|}{ Collinearity Statistics } \\
\hline & $\beta$ & Std. Error & & & & Tolerance & $\begin{array}{c}\text { Variance } \\
\text { inflation factor }\end{array}$ \\
\hline Intercept & -.755 & 1.239 & & -.610 & .542 & & \\
\hline BA & .113 & .022 & .581 & 5.136 & .000 & .714 & 1.400 \\
\hline RISK & -.049 & .016 & -.139 & -2.967 & .003 & .941 & 1.062 \\
\hline EFE & .024 & .041 & .027 & .586 & .558 & .955 & 1.047 \\
\hline EQ & .000 & .033 & .000 & -.011 & .991 & .952 & 1.050 \\
\hline LEV & 1.563 & .641 & .118 & 2.437 & .015 & .876 & 1.141 \\
\hline SIZE & -.254 & .091 & -.155 & -2.798 & .005 & .670 & 1.493 \\
\hline GROWTH & .062 & .043 & .067 & 1.438 & .151 & .947 & 1.056 \\
\hline DP & .195 & .153 & .059 & 1.280 & .201 & .971 & 1.030 \\
\hline
\end{tabular}

Adjusted R-Square $=0.605$, Durbin-Watson $=1.992$, F-value $=4.995($ Sig. $=0.000)$

According to the results of Table 1, F-value is equal to 4.995 and it is statistically significant, which means the relationship between independent and dependent variables are linear. In addition, DurbinWatson ratio is equal to 1.992, which indicates that there was no auto-correlation among residuals. Moreover, adjusted R-Square is equal to 0.605, which means the independent variables represent approximately $61 \%$ of the changes on dependent variable. Finally, there is a positive and meaningful relationship between unusual return as dependent variable and spread as independent variable (t-value $=5.136$, Sig. $=0.000)$. Therefore, the main hypothesis of the survey has been confirmed and we can conclude that there was a meaningful relationship between abnormal return and spread.

In order to examine the relationships between of the size of firm performance and spread, we have decided to categorize the performances in three groups of small medium and large. Table 2 shows the results of our survey,

Table 2

The summary of some statistics associated with small/medium and large firms

\begin{tabular}{ccccc}
\hline Group & Observations & Mean & Standard deviation & Mean error \\
\hline Small & 157 & 95.864673 & 59.5572274 & 4.7531842 \\
Medium & 157 & 98.629645 & 61.7491958 & 4.9281223 \\
Large & 157 & 89.913051 & 62.2507993 & 4.9840528 \\
\hline
\end{tabular}

We perform a statistical test among three groups of the firms and Table 3 presents the summary of our findings.

Table 3

The summary of t-student test among different pairs of observations

\begin{tabular}{ccccccc}
\hline Group & t-value & df & Sig. & Mean difference & Upper limit & Lower limit \\
\hline Small & 20.169 & 156 & .000 & 95.8646726 & 86.475767 & 105.253578 \\
Medium & 20.014 & 156 & .000 & 98.6296451 & 88.895187 & 108.364104 \\
Large & 18.040 & 155 & .000 & 89.9130512 & 80.067617 & 99.758485 \\
\hline
\end{tabular}


According to the results of Table 3, the mean performance for three groups of small, medium and large scale firms is different and we can conclude that spread for different sizes of return has had various impacts on earnings.

\section{Conclusion}

In this paper, we have presented an empirical investigation to study the relationship between spread and abnormal return for selected firms from Tehran Stock Exchange. The study has gathered the necessary information from official statements reported officially on exchange website. We have also used regression technique to examine the relationships. The results have indicated a positive and meaningful relationship between firm's abnormal return and spread. The results of this study are consistent with other findings. Fang et al. (2009) studied the relationship between stock liquidity and firm performance and reported that firms with liquid stocks had better performance as measured by the firm market-to-book ratio. To identify the causal effect of liquidity on firm performance, they studied an exogenous shock to liquidity - the decimalization of stock trading — and described that the increase in liquidity around decimalization could improve firm performance, which is somewhat the same as the result of this survey.

\section{Acknowledgement}

The authors would like to thank the anonymous referees for constructive comments on earlier version of this paper.

\section{References}

Amihud, Y., \& Mendelson, H. (1986). Liquidity and stock returns. Financial Analysts Journal, 42(3), 43-48.

Amihud, Y., \& Mendelson, H. (1989). The effects of beta, bid-ask spread, residual risk, and size on stock returns. Journal of Finance, 479-486.

Desai, A. S., Nimalendran, M., \& Venkataraman, S. (1998). Changes in trading activity following stock splits and their effect on volatility and the adverse-information component of the bid-ask spread. Journal of Financial Research,21(2), 159-183.

Demirovic, A., Tucker, J., \& Guermat, C. (2015). Accounting data and the credit spread: An empirical investigation. Research in International Business and Finance, 34, 233-250.

Fang, V. W., Noe, T. H., \& Tice, S. (2009). Stock market liquidity and firm value. Journal of Financial Economics, 94(1), 150-169.

Glosten, L. R., \& Harris, L. E. (1988). Estimating the components of the bid/ask spread. Journal of financial Economics, 21(1), 123-142.

Mishra, S., Rowe, W., Prakash, A., \& Ghosh, D. K. (2009). Spread behavior around board meetings for firms with concentrated insider ownership. Journal of Financial Markets, 12(4), 592-610.

Perrakis, S., \& Zhong, R. (2015). Credit spreads and state-dependent volatility: Theory and empirical evidence. Journal of Banking \& Finance, 55, 215-231.

Weber, K., Davis, G. F., \& Lounsbury, M. (2009). Policy as myth and ceremony? The global spread of stock exchanges, 1980-2005. Academy of Management Journal, 52(6), 1319-1347. 